\title{
Feasibility and perceptions of video tutorials for intern training in anaesthesia: a survey
}

\author{
L Naicker, ${ }^{1,2^{*}} \mathrm{~K}^{\mathrm{K}}$ Govender ${ }^{1,2}$ (D) and VS Singaram ${ }^{3}$ \\ 1 Prince Mshiyeni Memorial Hospital, Durban, South Africa \\ 2 Department of Anaesthetics, University of KwaZulu-Natal, Durban, South Africa \\ ${ }^{3}$ School of Clinical Medicine, University of KwaZulu-Natal, Durban, South Africa \\ *Corresponding author, email: Luansha.naicker@gmail.com
}

Background: Effective intern training is essential for safe delivery of anaesthesia during community service. Interns are trained using both tutorials and clinical exposure. E-learning platforms using video tutorials may address millennial learner needs better, but feasibility is unknown in a particular local setting. This study aimed to explore the feasibility of using a video tutorial to facilitate intern training. Perceptions of the value of tutorials were also assessed.

Methods: A cross-sectional survey was conducted amongst interns who rotated through anaesthesia at a regional hospital in KwaZulu-Natal. The interns had been exposed to face-to-face tutorials previously and provided with a video-based tutorial.

Results: Thirty-seven of the interns consented (88\%), watched the video and answered the questionnaire. All interns indicated a need for tutorials during internship. A majority of respondents (71\%) felt underprepared by undergraduate training programmes. Most interns were prepared to watch the video tutorial outside of working hours; however, they were divided over the fairness of using internet access for tutorials. There was a preference for video tutorials over reading a textbook or lecture notes. A total of $88 \%$ watched the video from the Internet. One intern did not have Internet access or a computer but the video was watched using a free Wi-Fi hotspot.

Conclusion: A video-based tutorial system is feasible but current infrastructure needs to be considered. Interns continue to feel underprepared for internship and request that tutorials continue in internship.

Keywords: anaesthesia training, e-learning, internship and residency, intern training, video tutorials

\section{Introduction}

Effective intern training is key for safe delivery of anaesthesia during community service. Community service is a 12-month period of State-only based practice to serve rural areas of need with doctors. ${ }^{1}$ Following a year of community service, doctors are able to register with the Health Professions Council of South Africa (HPCSA) as independent medical practitioners who may then practise in either the State or private health sectors. In South Africa, interns have a limited time to gain all the knowledge and skills necessary to be independent practitioners in anaesthesia during their community service and beyond. Internship was increased from one year to two years, and anaesthesia from two weeks to two months in 2008., ${ }^{2,3}$ This aimed to improve the safety, competence and preparedness of doctors for community service. However, Ash argues that increasing the duration of internship may not be the only answer to safer, more competent doctors. ${ }^{4}$ Interns continue to report being underprepared and poorly supervised during community service. ${ }^{5,6}$ In a survey of community service doctors by Kusel and colleagues, when asked about what they would change about their internship training, some requested more formal teaching. ${ }^{7,8}$

While suggestions have been made on how better to prepare interns, little focus has been given to matching the training to the generational teaching needs. Children born between the years 1980 and 2004 are known as Generation $Y$ or the millennial generation (millennials). ${ }^{9}$ Millennials tend to have increased accessibility to the Internet, a predisposition to gaming, excessive attachment to their mobile phones and are comfortable with social networking using technology. ${ }^{10}$ These younger generations tend to be taught by the older generation (traditional and baby-boomer generations), which Gillipsie termed, the 'generational gap.'11 This generational gap may be a barrier to effective teaching and training.

Newer techniques of postgraduate medical training need to be considered when developing and implementing improved teaching and training for the millennial learner. ${ }^{12}$ These learners tend to be independent thinkers who prefer technology as a medium for instruction, as they can control the time when they access the information, the pace and content. They are technology savvy, relying on multitasking for almost every activity in their lives. In medical education, millennials are referred to as the mobile and YouTube generation as they have grown up with modern information and communication technologies. ${ }^{13}$ Hence their mobile video consumption is greater than other generations as is the case of the majority of current interns. An electronic learning platform (e-learning) — also known as online learning or web-based learning-using video tutorials could address millennial student needs as well as increasing clinical exposure time, as less time is needed for face-to-face tutorials. Infrastructural limitations in low- to middle-income countries (LMICs) like South Africa could make application of this learning platform difficult. ${ }^{14}$

This study aimed to explore the feasibility of a video-based tutorial to facilitate intern tutorials. Perceptions of the video tutorial, the need for tutorials and previous exposure to e-learning were also evaluated. 


\section{Methods}

\section{Study population and location}

The study was conducted at Prince Mshiyeni Memorial Hospital, a regional-level hospital $17 \mathrm{~km}$ south of Durban, South Africa. There was a total of 72 interns for 2017: 44 were first-year and 28 were second-year interns. These interns all received their tutorials using a face-to-face format during 2017 and were therefore suitable to compare their own previous experience of a faceto-face tutorial with a video tutorial. Twenty-eight second-year interns were excluded. The second-year interns, having moved to their respective community service hospitals in 2018, would not be able to comment on the feasibility of video tutorials at our hospital.

\section{Video tutorial development}

The tutorial content comprised 10 topics developed from the Health Professions Council of South Africa's Intern Training Handbook. ${ }^{15}$ In February 2018 one of the 10 tutorials, i.e. the preoperative anaesthetic assessment, was chosen for development into a video tutorial. The tutorial covered only theoretical concepts with two examples of how the preanaesthetic record should be completed at our hospital (see Appendix A: Objectives of the Tutorial). A screen capture application called Explain Everything ${ }^{\oplus}$ (version 5.0.10S) on an Apple iPad Pro first generation was used. This application provides a whiteboard canvas on which one may write text, insert various media (pictures and video) and record a voiceover. This app was chosen as it was familiar to the team and it had the necessary features to produce the video, and also included a video and sound editor. This was then saved in an MPEG video format and distributed in various ways. The chosen methods for distribution were through a YouTube link or on a USB stick as a video file, which could be watched on a computer.

After the initial video tutorial production, the video was peer reviewed by other consultants in the department for face and content validity. Following suggestions, the initial video of 19 minutes was reduced to two videos totalling 13 minutes; one on theory ( 8 minutes) and the other on two examples of application of the theory ( 5 minutes). The video and questionnaire were also piloted amongst six interns for reliability and construct validity. The results from the pilot group were excluded from the study results. Post-video interview feedback from the pilot group was used to adjust the videos and questionnaire according to content, clarity, layout, length and ease of use.

\section{Video distribution and evaluation}

Following verbal telephone consent, the cohort of 44 firstyear interns were given a link to the YouTube video by email. If they were unable to watch the video from the Internet, they were invited to collect a USB stick with the videos on it from our department of anaesthetics in theatre. In March 2018, the cohort was given one week to watch the video, following which they were met and given a self-administered questionnaire (see Appendix B: Questionnaire). Interns were allowed a week to complete and return the questionnaire. They were advised to answer the questionnaire independently of each other and not discuss their responses, to prevent data contamination. Perceptions, value and feasibility of a video tutorial system were assessed using a five-point Likert scale. The questionnaire together with written consent was returned to the department of anaesthetics. The video may be accessed on YouTube at the following link: https://youtu.be/hUjqtzK1NAk

\section{Statistical evaluation}

A pragmatic sampling strategy of the 2017 interns, excluding second-year interns, created a sample size of 44 first-year interns. Quantitative data were summarised using descriptive statistics and the changes suggested were reported.

\section{Ethical considerations}

This study was approved by the UKZN BREC (BE447/17). Gatekeeper permission from the KwaZulu-Natal Department of Health was approved (46/RESH/2017). Participation was voluntary, and written consent was acquired as part of the questionnaire.

\section{Results}

A total of 42 interns consented to be part of the study and 37 returned completed questionnaires, a response rate of $88 \%$.

The interns' overall perception of tutorials, as well as their previous exposure to e-learning, is described in Figure 1. All interns indicated their need for tutorials during internship. Some $71 \%$ of respondents felt underprepared for internship by their respective undergraduate anaesthetic training programmes.

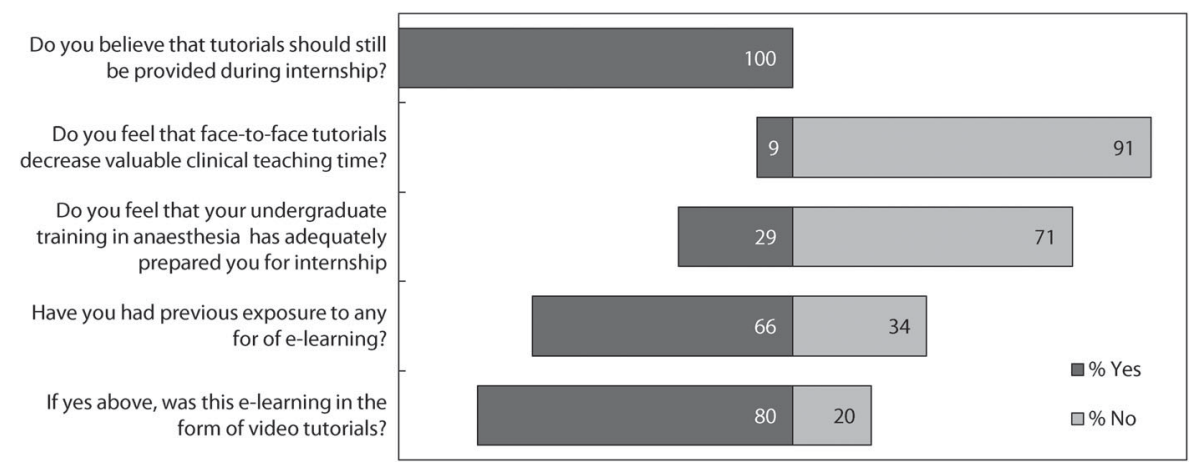

Figure 1: Interns' perceptions of tutorials and their previous exposure to e-learning. 


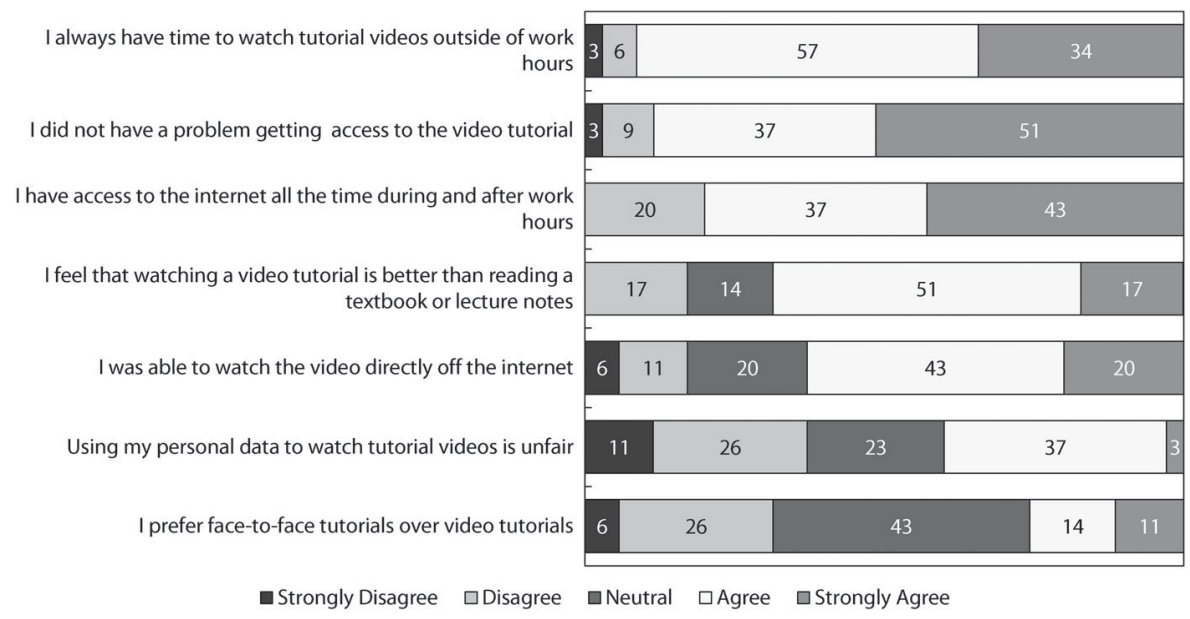

Figure 2: Feasibility of watching a video-based tutorial off the Internet assessed using a five-point Likert scale.

Most felt that tutorials did not decrease clinical exposure and training time.

The feasibility of using video-based tutorials is described in Figure 2. A large majority (81\%) of interns were prepared to watch the video tutorial after work but were divided over the fairness of having to use internet access to watch a video tutorial. Approximately one-third (32\%) of interns preferred video tutorials over face-to-face tutorials. Although $43 \%$ were unsure of their choice of video-based tutorials over face-to-face tutorials, $69 \%$ preferred video tutorials over reading a textbook or their lecture notes. Most interns (88\%) did not have a problem watching the video directly from the Internet. Three interns (9\%) requested the video tutorial on a USB stick. One intern (3\%) had neither the relevant internet access to watch the video nor a computer to watch it from a USB stick. We offered the intern a computer in the Department of Anaesthetics but the intern was resourceful enough to watch the video from the Internet at a free Wi-Fi hotspot.

The quality of the video is described in Figure 3 with mostly 'agree' and 'strongly agree' Likert ratings. No respondent scored any of the four categories as 'disagree' or 'strongly disagree'. The pace of the video was reported to be acceptable by $86 \%$ of interns; three interns (9\%) felt the video was too fast while two interns $(6 \%)$ thought it was too slow.

The open-ended question on how the video tutorial could be improved had only four responses. This was insufficient to be coded and summarised into themes. Comments included requests for shorter videos and more graphics and pictures. One intern wanted 'more engagement' and the other wanted 'more practical examples' but neither elaborated further.

\section{Discussion}

Our survey indicates that the typical respondent requests that tutorials continue during internship and has been exposed to some form of e-learning previously. Video tutorials were positively received, and interns are willing to use their personal time outside work to watch tutorials; however, infrastructure limitations and data (internet access via mobile phone) costs reduced the ability to watch the video directly from the Internet. The video tutorial produced for this study was of an acceptable quality to be viewed on a smartphone.

It has been reported previously that interns use tutorials during internship to compensate for the deficiencies of medical school. ${ }^{7}$ While clinical exposure and supervised practice tend to be the focus of internship, $91 \%$ believed that tutorials do not decrease clinical exposure time. With a shift to videobased tutorials even more time may be dedicated to clinical teaching; this is a consistent recommendation in surveys on how internship could be improved. $5,8,16$

Just under two-thirds of interns had been exposed to an e-learning training platform previously; most of these experiences were in the form of video tutorials. This demonstrates how undergraduate training has shifted from lecture-style methods to exploring e-learning based methods to better suit modern learning styles. ${ }^{10,11}$ For interns who have not been exposed to

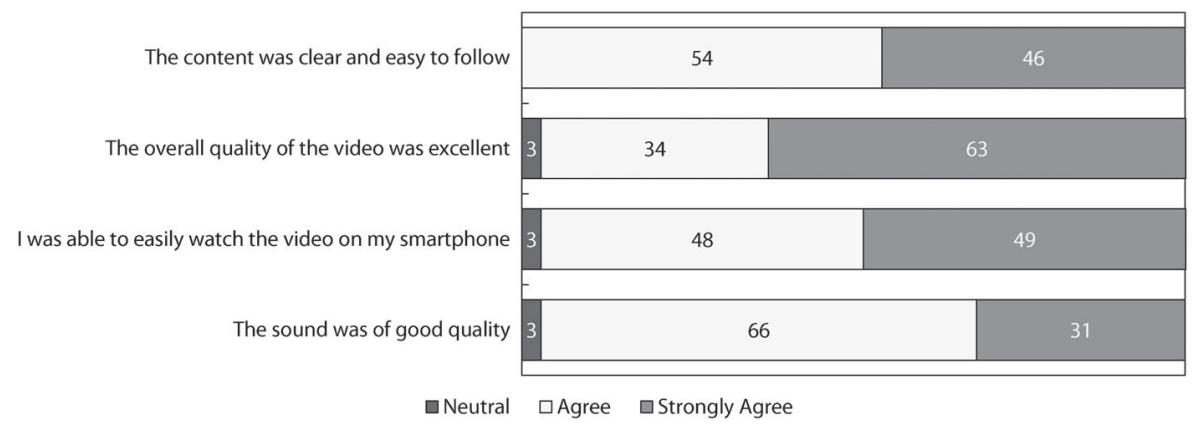

Figure 3: Intern perceptions of the video quality using a five-point Likert scale. 
e-learning or video tutorials previously, watching videos from the Internet or social media is ubiquitous nowadays and success is achieved with little effort, even by the previously uninitiated.

Generation $Y$ learners have been described as learners who extend themselves past the work day to read patient notes, follow up on patient results and use online resources to read around patients. ${ }^{12}$ This is in keeping with our study where $91 \%$ of interns are willing to watch tutorial videos outside working hours. Most interns prefer video tutorials as compared with faceto-face tutorials but they are divided over whether these will be able to replace face-to-face contact. Some benefits derived from face-to-face tutorials are the ability to immediately clarify misconceptions and the fact that face-to-face tutorials also provide a break out of the theatre environment, which may cause attention fatigue and claustrophobia to new theatre practitioners. ${ }^{17}$ Another advantage of a video tutorial system is that interns will not miss tutorials if they are not present at the time of the tutorial. They will have access to the tutorials during the anaesthetic rotation as well as after internship. This may assist interns who have reduced confidence in community service having done anaesthesia early in their first year of internship.

The production of a video tutorial encompasses three phases: (1) capture, (2) editing and (3) distribution. Video capture can be done in a number of ways. The major limiting factors include: hardware availability, software availability and technical knowhow. A screen capture application on a tablet device was chosen for this study as it mimics the whiteboard in the faceto-face tutorials and was relatively easy to use. Screen capture applications range from free apps to paid-for apps. Explain Everything ${ }^{\circledR}$ costs approximately R350 per year via the Apple ${ }^{\circledast}$ App Store. This application had more features than other free screen capture apps. In addition, unlike YouTube videos and Internet alternatives to video tutorial production, this App included basic video and sound editing. This precluded the need for additional expenses related to obtaining a separate video editor application. Video editing software can be very costly and challenging for novices and is usually the biggest hurdle for the occasional video tutorial enthusiast.

To make distribution of the video tutorial feasible, we needed a balance between quality and size of the video in megabytes (MB). A good quality video would appear clearer on a bigger screen, have a larger file size and therefore would be more difficult and costly to distribute and watch. We first reduced the duration of the video and then decided to compromise on resolution to prioritise a smaller file size while trying not to affect quality. The lower resolution targeted the smartphone screen resolution, which we believed to be the predominant method of viewing the video. When a smartphone was used, most reported excellent quality, easy viewing and good audio. The video was distributed on the Internet via YouTube as this is well known to many, easy to access and use, and is commonly used to distribute many medical teaching videos. ${ }^{13}$
Developing countries are most commonly affected by infrastructural constraints. However, in a review of e-learning publications in 2013 by Frehywot and colleagues, South Africa ranked fourth among LMICs in most published articles on e-learning programmes, following Brazil, India and Egypt. ${ }^{14}$ Other e-learning problems include: reduced skills in design and implementation, lack of institutional financial support for hardware and software, limited resources in terms of Internet access, device availability, power cuts and developing a receptive culture for e-learning through support of students and faculty development. ${ }^{18,19}$

E-learning platforms can therefore be difficult to introduce and implement. LMICs like South Africa have problems of low bandwidth, difficulties watching videos from a computer screen, slow Internet speeds, inadequate computer facilities and frequent power failures. ${ }^{14}$ While e-learning platforms may be better for both the teaching and learning of millennial students, infrastructure limitations may continue to hinder application of the learning platform.

Since November 2017, Internet access and cellphone reception has greatly improved at our hospital. Some $62 \%$ of the interns were able to watch the video directly from the Internet. High data (internet access) costs may have limited some interns with regard to Internet access. The other interns received the video on a USB stick. One intern watched the video via free Wi-Fi. Accessing free Wi-Fi hotspots outside the hospital will not be an expectation of our tutorial programme though millennial learners tend to be resourceful when it comes to their learning. It was noted that $40 \%$ of interns felt that using internet access to watch tutorial videos is unfair. This may be overcome by distribution on USB sticks. Having access to tutorials in this way increases clinical exposure time and overcomes missed tutorials for interns who are on leave, unwell or pre- or post-call.

Our study has implications for improving the quality of intern training in anaesthesia using a modern teaching style to address millennial learners while providing them with ongoing support and access to tutorials once the full tutorial programme has been converted to a video-based tutorial system.

\section{Limitations}

While our study was novel with regard to using video-based tutorials for training interns in anaesthesia, we had a number of limitations. One index video was used to assess feasibility and perceptions. Interns might feel differently if they had to watch all 10 tutorials from the Internet. Solutions on how this may be addressed have been suggested. We did not assess device preferences. If smartphones were the preferred device then videos may be produced in a smaller size, which decreases internet usage and cost. However, distributing videos on a USB stick would overcome this limitation on size and cost of internet usage. The value placed on tutorials is disproportionately high. Knowledge gained as undergraduate students was probably not internalised and valued. Now that interns are actually 
undertaking anaesthesia, they realise how important it is and place greater value on any teaching, including videos.

\section{Future research}

Blended learning is a teaching technique that combines online material with traditional classroom methods. A subtype of blended learning is the flipped classroom model, also known as flipped learning, which reverses the traditional learning environment. It moves traditional teaching to online lectures and homework activities into interactive classroom sessions. Video tutorials used in blended or flipped learning models would engage and facilitate active learning in medical interns. Active learning includes approaches that focus more on developing students' skills than on transmitting information and require that students do something - read, discuss, write - that requires higher-order thinking. They also tend to place some emphasis on students' explorations of their own attitudes and values. ${ }^{20}$ Blended learning used for training residents in anaesthesia and critical care had a positive effect on active learning and information retention. ${ }^{21} \mathrm{~A}$ systematic review and meta-analysis by Liu et al. showed a consistently positive effect on learning of blended learning instruction as compared with non-blended learning forms of teaching. ${ }^{22}$ As our video creativity and infrastructure improves, it would be interesting to investigate the effect on learning and knowledge retention by incorporating a full video-based tutorial system within a flipped learning model for intern anaesthesia training in our setting.

\section{Conclusion}

Tutorials are requested and valued as undergraduate training leaves graduates underprepared for internship. E-learning through video tutorials may better address millennial learner needs. A video-based tutorial system is feasible though current infrastructure needs consideration and improvement.

Disclosure statement - No potential conflict of interest was reported by the authors.

\section{ORCID}

K Govender (D) http://orcid.org/0000-0003-3996-3659

\section{References}

1. Reid SJ, Peacocke J, Kornik S, et al. Compulsory community service for doctors in South Africa: a 15-year review. S Afr Med J. 2018;108(9):741-7.

2. Meintjes Y. The 2-year internship training. S Afr Med J. 2003;93(5):336-7.

3. Prinsloo A. A two-year internship programme for South Africa. S Afr Fam Pract. 2005;47(5):3.

4. Ash S. A comparison of two-months versus two-weeks of internship anaesthesia training. S Afr J Anaesth Analg. 2009;15(1):23.

5. Kusel B, Farina Z, Aldous C. Practising anaesthesia as a community service doctor: a survey-based assessment. S Afr J Anaesth Analg. 2017;23(2):45-9.

6. Nkabinde TC, Ross A, Reid S, et al. Internship training adequately prepares South African medical graduates for community service - with exceptions. S Afr Med J. 2013;103(12):930-4.

7. Kusel B, Farina Z, Aldous C. Creating the perfect intern anaesthesia rotation: a survey using feedback from past interns. S Afr J Anaesth Analg. 2017;23(2):50-5.

8. Bola S, Trollip E, Parkinson F. The state of South African internships: a national survey against HPCSA guidelines. S Afr Med J. 2015;105 (7):535-9.

9. Borges NJ, Manuel RS, Elam CL, et al. Comparing millennial and generation $X$ medical students at one medical school. Acad Med. 2006;81 (6):571-6.

10. Hills $C M$, Levett-Jones $T$, Lapkin $S$, et al. Generation $Y$ health professional students' preferred teaching and learning approaches: a systematic review. Open J Occup Ther. 2017;5(1):23.

11. Gillispie V. Using the flipped classroom to bridge the gap to generation $Y$. Ochsner J. 2016;16(1):32-6.

12. Evans KH, Ozdalga E, Ahuja N. The medical education of generation Y. Acad Psychiatry. 2016;40(2):382-5.

13. Potomkova J, Mihal V, Schwarz D. Medical education for YouTube generation. E-Learning-Engineering, On-Job Training and Interactive Teaching: InTech; 2012.

14. Frehywot S, Vovides $Y$, Talib $Z$, et al. E-learning in medical education in resource constrained low- and middle-income countries. Hum Resour Health. 2013;11:4-19.

15. Health Professions Council of South Africa. Medical and dental professions board's handbook on internship training. 2017 [cited 2018 Aug 24]. Available from: http://www.hpcsa-blogs.co.za/ medical- and-dental-professions-boards-handbook-on-internship-training/

16. Lamacraft G, Kenny PJ, Diedericks BJ, et al. Training and experience of doctors administering obstetric anaesthesia in the free state level 1 and 2 hospitals. S Afr J Anaesth Analg. 2008;14(2):13-7.

17. Gregory P, Edsell M. Fatigue and the anaesthetist. Continuing Educ Anaesth Crit Care Pain. 2014;14(1):18-22.

18. Gupta $M$, Marsden S, Oluka $T$, et al. Lessons learned from implementing e-learning for the education of health professionals in resource-constrained countries. Electron J e-Learning. 2017;15(2): 144-55.

19. O'Doherty D, Dromey M, Lougheed J, et al. Barriers and solutions to online learning in medical education - an integrative review. BMC Med Educ. 2018;18(1):130-41.

20. Bonwell CC, Eison JA. Active learning: creating excitement in the classroom. 1991 ASHE-ERIC Higher Education Reports: ERIC; 1991.

21. Marchalot A, Dureuil B, Veber B, et al. Effectiveness of a blended learning course and flipped classroom in first year anaesthesia training. Anaesth Crit Care Pain Med. 2018;37(5):411-5.

22. Liu $Q$, Peng W, Zhang $F$, et al. The effectiveness of blended learning in health professions: systematic review and meta-analysis. J Med Internet Res. 2016;18(1):1-18. 


\section{Appendix A: Outline and objectives for the tutorial converted into a video tutorial}

Topic: Preoperative anaesthetic assessment

\section{Objectives:}

\section{(i) Video Tutorial Part 1:}

Following this tutorial, you should be able to:

1. Take an appropriate history from a patient
a. Presenting complaint
b. Past medical and surgical history
c. Allergies and medications
d. Social and family history
e. Systemic enquiry, especially: effort tolerance, reflux, dyspnoea, blackouts and chest pain

2. Know the importance of a focused exam
a. General and airway assessment
b. Respiratory exam
c. Cardiovascular exam
d. Other relevant systems, e.g. back for spinals

3. Evaluate investigations and order appropriate investigations with the help of a senior

4. Construct a basic anaesthetic plan for the patient

5. Understand the role of premedication and the management of chronic medication with the help of a senior

(ii) Video Tutorial Part 2:

Following this tutorial, you should be able to:

1. Know the format and shortcomings of the current anaesthetic record a. Abbreviate essential positive and negative findings from the clinical assessment

2. Know how to complete the form with the above information

a. Example 1: Caesarean section for foetal distress

b. Example 2: Exploratory laparotomy (GSW abdomen) 


\section{Appendix B: Questionnaire}

Questionnaire: Intern Tutorials and Video Tutorial Evaluation 2018

\section{Part 1: Value of tutorial during internship:}

1. Do you believe that tutorials are important during your block rotation through anaesthetics?

\section{YES / NO}

2. Do you feel that tutorials waste time that you could be spending in theatre with a senior and a patient? YES / NO

3. Do you feel that your undergraduate training in anaesthesia was adequate to prepare you for internship supervised practice in theatre?

\section{YES / NO}

\section{Part 2: Background exposure to e-learning:}

Have you ever had any exposure to:

4. any form of e-learning?

\section{YES / NO}

5. video-based tutorials?

YES / NO

6. Internet-based tutorials?

YES / NO

7. an electronic/computer-based assessment?

\section{YES / NO}

8. How much time do you have to watch video tutorials outside of work time?
1. I have no time
2. I don't have much time
3. Not sure
4. I can make some time
5. I do have time

\section{Part 3: Technological challenges}

9. There was a problem getting the video.
1. Strongly disagree
2. Disagree
3. Not sure
4. Agree
5. Strongly agree

10. I prefer to watch the video directly off the YouTube website at my leisure.
1. Strongly disagree
2. Disagree
3. Not sure
4. Agree
5. Strongly agree

11. Using my internet access to watch the videos is unfair.
1. Strongly disagree
2. Disagree
3. Not sure
4. Agree
5. Strong agree

12. How often do you have access to the Internet?
1. Never
2. Not often
3. Not sure
4. Most of the time
5. All the time 


\section{Part 4: Tutorial video content}

13. The tutorials videos were easy to watch.
1. Strongly disagree
2. Disagree
3. Not sure
4. Agree
5. Strongly agree

14. The content was clear and easy to follow.

2. Disagree

3. Not sure

4. Agree

5. Strongly agree

15. The video was easy to watch on my phone or laptop.
1. Strongly disagree
2. Disagree
3. Not sure
4. Agree
5. Strongly agree

16. The video was clear and easy to hear.
1. Strongly disagree
2. Disagree
3. Not sure
4. Agree
5. Strongly agree

17. The pace of the video was adequate for me to follow.
1. Too slow
2. Slow
3. Just right for me
4. Fast
5. Too fast

18. The overall quality needs improvement?

$\begin{array}{lllll}\text { 1. The video needs to be scrapped } & \text { 2. The video needs to be changed completely } & \text { 3. Not sure } & \text { 4. Some improvement } & \text { 5. No changes. It's good }\end{array}$

What changes do you suggest:

19. I prefer classical teaching style tutorials and not video tutorials:
1. Strongly disagree
2. Disagree
3. Not sure
4. Agree
5. Strongly agree

\section{Other aspects:}

20. Did you feel that watching a video is better than reading a textbook or lecture notes?
1. Strongly disagree
2. Disagree
3. Not sure
4. Agree
5. Strongly agree 